\title{
An Experimental Investigation on Concrete by Partial Replacement of Coarse Aggregate and Fine Aggregate by Rubber TYRE and Steel Slag
}

\author{
Sreesha. S \\ Department of Civil Engineering, \\ Sri Krishna College of Technology, \\ Coimbatore-641042, India
}

\author{
Esakkiraj. P \\ Department of Civil Engineering, \\ Sri Krishna College of Technology, \\ Coimbatore-641042, India
}

\author{
Manoj Prabaakar. S \\ Department of Civil Engineering, \\ Sri Krishna College of Technology, \\ Coimbatore-641042, India
}

\begin{abstract}
In India between 7.7 and 8.3 million tons of steel slag are expected to be produced per year. The accumulated waste pipes of the various solid waste have become a problem of interest due to their non-biodegradable nature. In other sectors, such as thermal power plants or cement kilns and stainless-steel ovens, most waste tyre rubbers are used as heat. Unfortunately, this method of usage is not eco-safe and expensive. Therefore, the usage of scrap tyre rubber in concrete construction was deemed effective waste management to safeguard the climate. The usage of this waste product will reduce the cost of concrete by partly substituting the coarse and fine aggregates. The primary goal of this research is to experimentally study the effects on the various strength properties of concrete by using the M30 mix design, of a partial replacement of fine aggregates with steel slag and ground aggregate with rubber tyre. The research specimen of $0 \%, 5 \%, 10 \%, 15 \%$ is casted and checked for compressive strength and Split tensile strength after a 7 day, 14 days, and 28 days curing time, $20 \%$ of the partial replacement by steel slag and coarse aggregate by rubber tyre.
\end{abstract}

Keywords - Rubber Crumbs, Steel Slag, Compressive Strength, Flexural Strength, Split Tensile Strength

\section{INTRODUCTION}

Concrete is a structural material consisting of a fine and coarse aggregate confined to a fluid matrix which, after some time, solidifies. Mainly, the fine aggregate used worldwide is river sand and because of the transport and depletion, it is expensive. The question of waste management is rising. In the present work, new construction material from a steel slag is to be made, a waste lathe as a replacement material for fine concrete aggregate. This helps to meet the objective of reducing building costs and helps to solve the problem of disposal in the region, including environmental problems. The key research parameter is the substitution of sand by steel slag and coarse aggregate by rubber tyre. Tyres are complicated engineering products. They consist of numerous rubber compounds, various kinds of black carbon, fillers such as clay and silica, and chemicals and minerals that allow or speed up vulcanization.

Tyres are manufactured for automotive usage and are not generated as feed-stock for the recycling industry. They are difficult to recycle because of their composition. Wastes in the form of steel scraps and steel slag that can be produced by the lath machines in the process of the preparation of the different parts of the machinery are available in each lath industry, and these wastes are dumped on the unhealthy land contaminated by the land and groundwater. These steel slags were now used for days as a waste product for innovative construction, transportation, and the motorway industry. Besides they are expected to use the lathe as worn-recycle fibers for concrete in tandem for economic development and environmental remuneration.

S. T. Borole et.al (2016) concluded in their experimental work on concrete grade M30 that the compressive strength, the Split tensile strength, the flexural strength increased by $25 \%$ by fine aggregate weight in the percentage of steel slag and then decreased considerably in the further replacement of steel slag in concrete. Eco-friendly and mass use of waste materials in construction is possible with the use of steel slag for partial substitution of concrete.

S. P. Palanisamy et. al (2015) indicated the usage of steel slag, wastes of cheap natural materials used as fine aggregates for cement grades of M55, and recommends and accepts products for use in cement as substitutions of fine aggregates. The partial replacement of natural aggregates allows the gain of compressive, tensile, and flexural resistance and modulus of concrete elasticity up to an optimum value of a replacement. The substitution of fine aggregates in compression and strain by steel slag by up to 36 percent has been reported, while the concrete characteristics of the same proportion of steel slag and standard fine applied aggregate have been verified as inefficient. Benefits can often arise from energy reductions, social benefits, and the widespread usage of waste products as a raw source for fine concrete by utilizing steel slag.

GozdeInanSezer et. al(2015) conducted their experimental study by substitute steel slag for fine aggregates and/or coarse aggregates. The authors concluded that both fine and coarse aggregates in separate combinations will replace the steel slag but can not be substituted for fine or coarse aggregates in a single mix. They indicated that steel slag could be used more advantageously as a coarse aggregate rather than as a supplement for fine aggregate. The increase in the substitution percentage increased the concrete weight Compared to traditional concrete, an improvement in the flexural strength of concrete was found.

Prof. Subathra Devi et al. (2014) conducted an experimental investigation on M20 concrete. On testing workability using a slump cone test, the workability of the concrete has been concluded to decline gradually as the percentage of fine aggregate replacement increases. Concerning strength parameters, the author has suggested that 
the strength parameters improve in proportion compared with standard concrete, compressive, tensile, and flexural stress measures. Durability tests were carried out in this study, such as resistance to acid using $\mathrm{HCl}, \mathrm{H}_{2} \mathrm{SO}_{4}$, etc. After immersion in acids, the mass loss in cubes is very low.

Goulias et al (1998) performed an experimental analysis involving crumb rubber as a fine aggregate with Portland cement. The results of the test revealed improvements in the fragile concrete failure and indicated a better output of the rubber concrete experiments than that of the standard concrete. Without the full disintegration of the concrete, the results showed a major deformation. In Biel and Lee (1996), recycled tyre rubber was used in concrete mixtures made of magnesium oxychloride cement, where the aggregate was replaced by fine crumb rubber up to $25 \%$ by volume. Compressive and tensile strength testing found that magnesium oxychloride cement can be better associated.

Khatib et al (1999) concluded that mixtures may be made up of CA and FA employing a ground tyre. supported its workability, an overall volume of fifty percent may be used. The strength data developed (compressive and flexural) in their study shows that the strength is systematically reduced by the rise in rubber content. From a practical point of view, because of the severe reduction of strength, rubber content shouldn't exceed 20 percent of the overall volume.

\section{MATERIALS USED}

\section{A. CEMENT}

Cement is a binder, a substance that sets and hardens and may bind other materials together. It plays a very important role in concrete because it's the one that binds the aggregates together by the use of water. Here during this project OPC grade, 53 is employed to conduct the experimental study. The OPC grade 53 cement has compressive strength not but $53 \mathrm{MPa}$ as per BIS requirements. This cement produces highgrade concrete at very economical cement content. Cement might be concentrated to 10 you choose the use of OPC grade 53.

Table 1 Properties of Cement

\begin{tabular}{|c|l|c|}
\hline S. No. & \multicolumn{1}{|c|}{ Properties } & Values \\
\hline 1. & Specific Gravity & 3.17 \\
\hline 2. & Consistency & $30 \%$ \\
\hline 3. & Initial Setting Time & $35 \mathrm{~min}$ \\
\hline
\end{tabular}

\section{B. FINE AGGREGATE}

The natural river sand is that the most ordinarily used fine aggregate in concrete. The properties of sand will affect the strength of concrete in a great manner. The fine aggregate shouldn't have high clay and silt content since clay will affect the behavior of cement and reduces the strength of concrete. The fine aggregate should even be free from any organic content.

Table 2 Properties of Fine aggregate

\begin{tabular}{|c|l|c|}
\hline S. No. & \multicolumn{1}{|c|}{ Properties } & Values \\
\hline 1. & Specific Gravity & 2.67 \\
\hline 2. & Fineness Modulus & 2.25 \\
\hline
\end{tabular}

\section{COARSE AGGREGATE}

Aggregates are the foremost mined materials within the world. Aggregates are a component of composite materials like concrete. the combination is a reinforcement to feature strength to the general material. thanks to the relatively high hydraulic conductivity value as compared to most soils, aggregates are widely utilized in drainage applications like foundation and French drains, septic drain fields, wall drains, and roadside edge drains. Aggregates are used as base material under foundations, roads, and railroads. In other words, aggregates are used as a stable foundation or road/rail base with predictable, uniform properties (e.g. to assist prevent differential settling under the road or building), or as a low-cost extender that binds with costlier cement or asphalt to create concrete. The coarse aggregate is collected from the local area.

Table 3 Properties of Coarse aggregate

\begin{tabular}{|c|l|c|}
\hline S. No. & \multicolumn{1}{|c|}{ Properties } & Values \\
\hline 1. & Specific Gravity & 2.80 \\
\hline 2. & Impact value & $14.15 \%$ \\
\hline
\end{tabular}

\section{RUBBER CRUMBS}

Tyres are products of complex engineering. they're made from numerous different rubber compounds, many alternative kinds of lampblack, fillers like clay and silica, and chemicals $\&$ minerals added to permit or accelerate vulcanization. Now a day's these rubber tyres as a waste matter utilized by innovative construction industries.

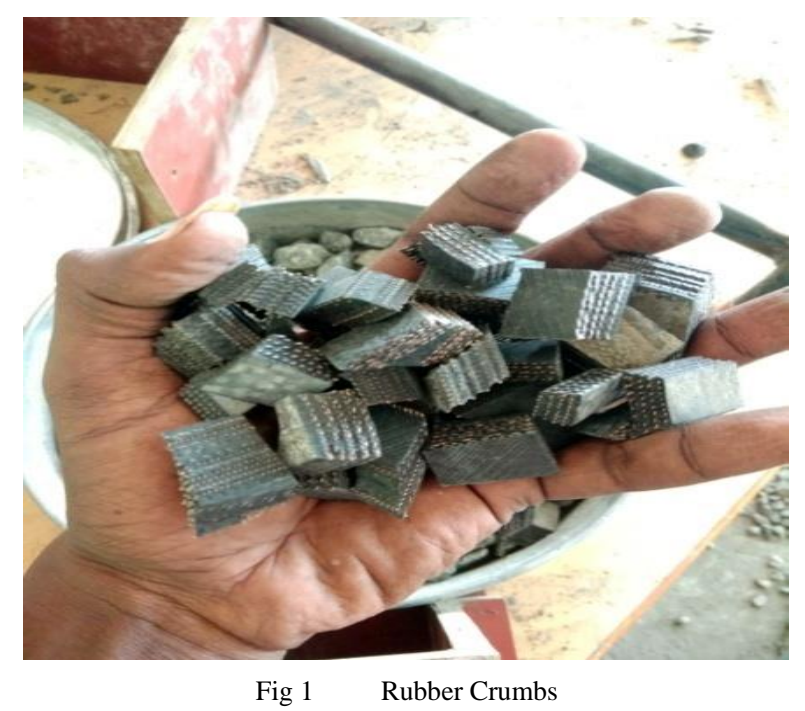

Table 4 Properties of Rubber crumbs

\begin{tabular}{|c|l|c|}
\hline S. No. & \multicolumn{1}{|c|}{ Properties } & Values \\
\hline 1. & Specific Gravity & 1.15 \\
\hline 2. & Fineness Modulus & 4.2 \\
\hline
\end{tabular}

\section{E. STEEL SLAG}

In each lathe industry, wastes are available in sort of steel scraps and steel slags which are yield by the lathe machines in the process of finishing various machines parts and dumping of those wastes. Now a day's these steel slags as a waste matter utilized by innovative construction industries. 


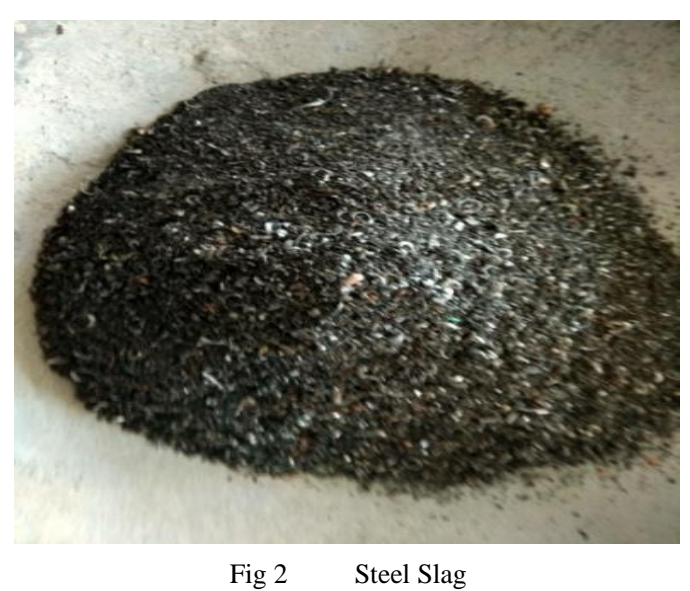

Table 5 Properties of Steel Slag

\begin{tabular}{|c|l|c|}
\hline S. No. & \multicolumn{1}{|c|}{ Properties } & Values \\
\hline 1. & Specific Gravity & 2.85 \\
\hline 2. & Fineness Modulus & 0.21 \\
\hline
\end{tabular}

\section{MIX DESIGN}

The mix composition is chosen to satisfy all performance criteria for the concrete in both the fresh and hardened states. Proportioning of concrete mixes may be thought to be a procedure set to proportion the foremost economical concrete mix for specified durability and grade for required site conditions. the fundamental principle of the concrete mix design is to pick the proportion of all the ingredients the premise of the irresolute volume mix design is for $1 \mathrm{~m} 3$ of concrete (as shown within the Table 6) with the partial replacement of fine aggregate and coarse aggregate by Steel Slag and Rubber Crumbs. The mix proportion of rubber crumbs and steel slag is as shown in Table 7.

Table 6 Mix Design

\begin{tabular}{|c|c|c|c|}
\hline Water & Cement & Fine Aggregate & $\begin{array}{c}\text { Coarse } \\
\text { Aggregate }\end{array}$ \\
\hline 186 & 426.67 & 826.58 & 1051.23 \\
\hline 0.40 & 1 & 1.9 & 2.5 \\
\hline
\end{tabular}

Table 7 MIX PROPORTION

\begin{tabular}{|c|c|c|}
\hline MIX & Rubber Crumbs & Steel Slag \\
\hline M0 & 0 & 0 \\
\hline M1 & 5 & 10 \\
\hline M2 & 10 & 15 \\
\hline M3 & 15 & 20 \\
\hline
\end{tabular}

\section{RESULTS AND DISCUSSION}

\section{A. FRESH CONCRETE TEST}

The fresh concrete property of concrete was estimated through the slump test and compaction factor. The slump values are shown in Fig 3. For achieving better workability, the slump value for this study was fixed within the range of $75 \mathrm{~mm}-100 \mathrm{~mm}$ i.e., moderate workable. The compaction factor is shown in Fig 4.

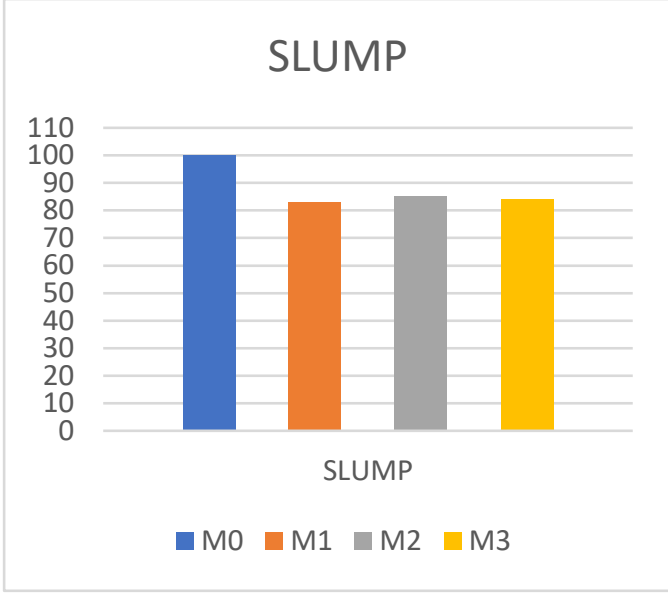

Fig 3 Slump test

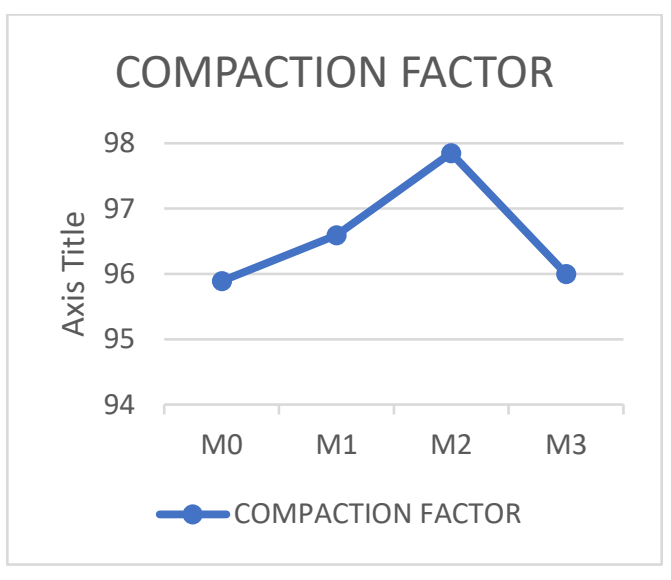

Fig 4 Compaction Factor

\section{A. COMPRESSIVE STRENGTH}

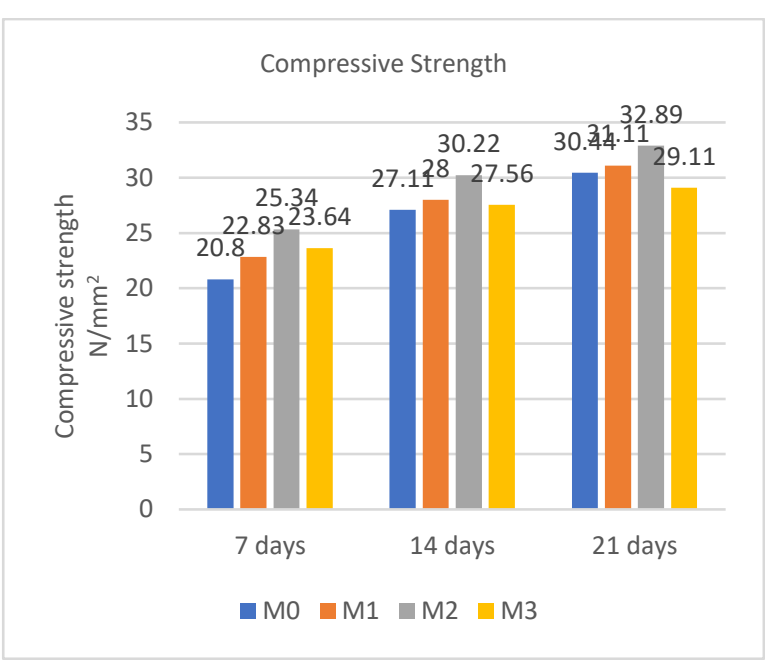

Fig 5 Compressive Strength

The cube specimens were tested in a very compressive testing machine and also the compressive strength of concrete was observed that the strength was decreased when an increase in the percentage of Rubber Crumbs and Steel Slag. Hence, we can adopt a minimum percentage of $10 \%$ of rubber crumbs and $15 \%$ of Steel Slag utilized in replacement of aggregate. 


\section{B. SPLIT TENSILE STRENGTH}

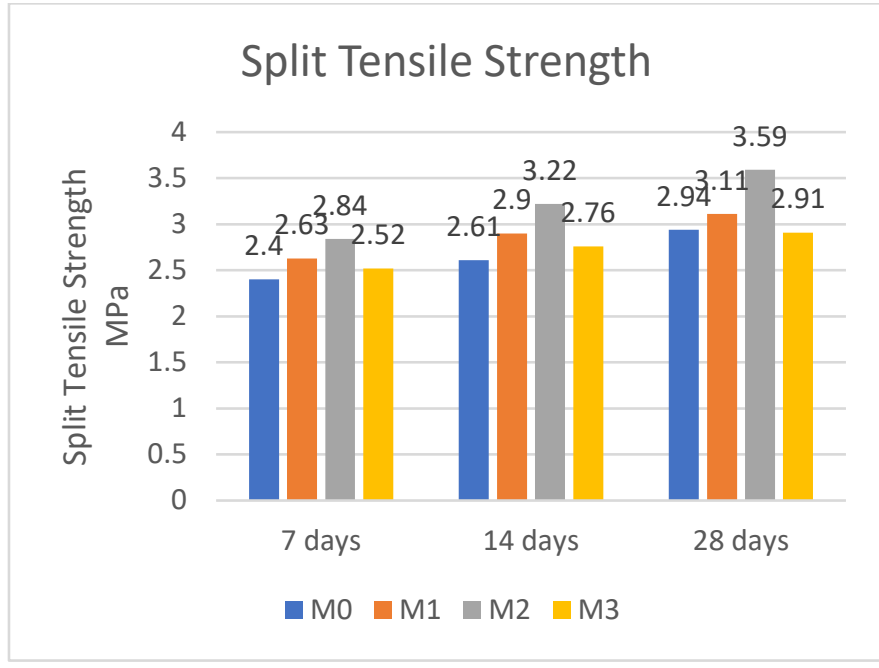

Fig 6 Split Tensile Strength

The cylinder specimens were tested in the compressive testing machine. The load is given in the periphery of the cylinder and split strength was observed. The strength is additionally reduced when the share of Rubber crumbs and Steel Slag is increased.

\section{FLEXURAL STRENGTH TEST}

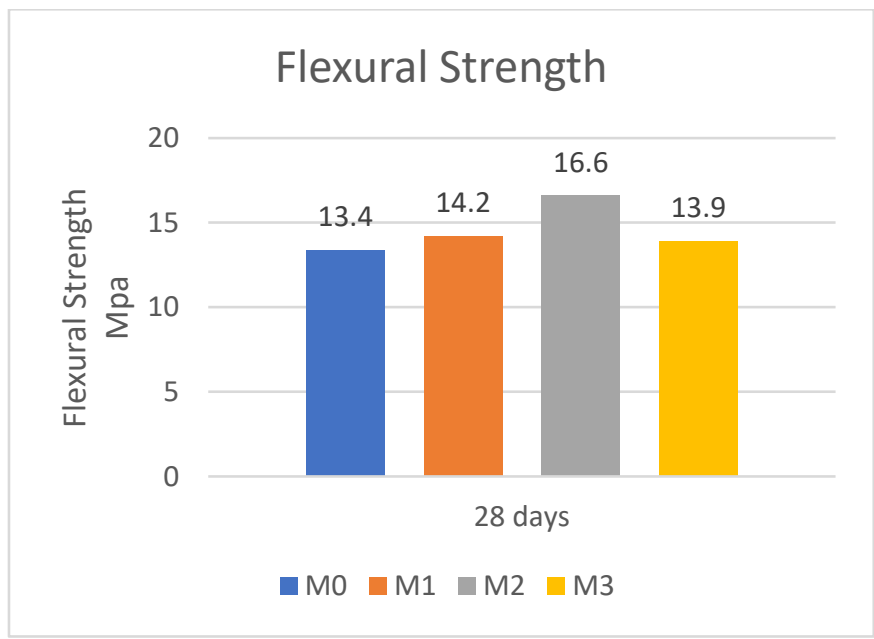

Fig $7 \quad$ Flexural Strength

Prisms were used for flexural strength and it had been observed that flexural strength encompasses a considerable increase for the combination M2. Hence, we will adopt a minimum percentage of $10 \%$ of rubber crumbs and $15 \%$ of Steel Slag employed in replacement of aggregate.

\section{CONCLUSION}

From the above Figures the result obtained after casting the concrete and the optimum percentage for partial replacement of coarse aggregate and fine aggregate with rubber tyre and steel slag is $10 \%$ and $15 \%$ The results (as shown in Fig 5, Fig 6, Fig 7) obtained from compressive strength, Split tensile strength and flexural strength is satisfactory approximately greater than the conventional concrete strength. The strength of concrete is compared with the collected literatures to get an ideal view on the strength obtained.Careful handling, placing and curing of this concrete mix may show increase in strength than the conventional concrete.The workability behaviour of the concrete achieved as same as the nominal concrete.From the result observation the mode of failure is because of bonding failure.

\section{REFERENCES}

[1] S.T. Borole, R.V. Shinde, R.B. Mhaske, S.S. Pagare, K.S Tribhuvan, N.M. Pawar, V.D. Tiwari, A.K. Sanehi, (2016), "Replacement of Fine Aggregate by Steel Slag." International Journal of Innovative Research in Science and Engineering. 2(3) 628-635.

[2] S.P. Palanisamy, G. Maheswaran, M.G.L. Annaamalai, P.Vennila (2015), "Steel Slag to Improve the High Strength of Concrete."International Journal of ChemTech Research. 7(5), 2499 2505.

[3] GözdeInanSezer and MertGülderen (2015), "Usage of Steel Slag in concrete as Fine and/or Coarse aggregate" Indian Journal of Engineering \& Materials Sciences. vol 22, 339-344

[4] V.Subathra Devi, B. K. Gnanavel, (2014) "Properties of concrete manufactured using steel slag" Procedia Engineering 97, 95-104.

[5] Goulias, D. G., and Ali, A. H. 1998!. "Evaluation of rubber-filled concrete and correlation between destructive and nondestructive testing results." Cem. Concr. Aggregates, 20 1!, 140-144.

[6] Biel, T. D. and Lee, H. (1996). "Magnesium oxychloride cemen concrete with recycled tire rubber." Transportation Research Record: Journal of the Transportation Research Board No. 1561, Transportation Research Board, Washington DC, pages 6-12.

[7] Khatib, Z. K., and Bayomy, F. M. 1999!. "Rubberized Portland cement concrete.'” J. Mater. Civ. Eng., 11 3!, 206-213.

[8] Ahirwar, K. (2009). Waste tyre rubber as coarse aggregate replacement in cement concrete. Master thesis in Structura Engineering, Civil engineering Department, and IIT Kharagpur.

[9] Bakri, A. M. M. A., Fadli, S. A. S. N., Bakar, M. D. A., and Leong, K. W. (2007). Comparison of rubber as aggregate and rubber as filler in concrete, First International Conference on Sustainable Materials 2007, Penang.

[10] Ganjian, E., Khorami, M., Maghsoudi, A. K. (2008). Scrap-tyre rubber replacement for aggregate and filler in concrete, Construction and Building Materials.

[11] Huang, B., Li, G., Pang, S., and Eggers, J. (2004) Investigation into waste tyre rubber-filled concrete. Journal of Materials in Civil

[12] IS 2386 (Part 3): 1963 - Methods of test for Aggregates for Concrete

[13] IS 383: 1970 - Specifications for Coarse and Fine Aggregates from natural sources for concrete

[14] IS 456: 2000- Plain and Reinforced Concrete Code of Practice

[15] IS 516:1959 (Reaffirmed 2004) - Methods of test for strength of concrete

[16] IS 10262-2009 - Concrete Mix Proportioning - Guidelines M S Shetty - Concrete Technology 